\title{
Identification of CaAN3 as a fruit-specific regulator of anthocyanin biosynthesis in pepper (Capsicum annuum)
}

\section{Jinyoung Byun}

Seoul National University

Tae-Gun Kim

Seoul National University

Joung-Ho Lee

Seoul National University

\section{Ning Li}

Hubei Academy of Agricultural Sciences

\section{Soyoung Jung}

Seoul National University

\section{Byoung-Cheorl Kang ( $\square$ bk54@snu.ac.kr)}

Seoul National University https://orcid.org/0000-0002-7606-7258

\section{Research Article}

Keywords: Anthocyanin, Fine-mapping, Capsicum, R2R3 MYB transcription factor, Transient overexpression, Virus-induced gene silencing.

Posted Date: February 9th, 2022

DOI: https://doi.org/10.21203/rs.3.rs-1283047/v1

License: (9) This work is licensed under a Creative Commons Attribution 4.0 International License.

Read Full License 


\section{Identification of $\mathrm{CaAN3}$ as a fruit-specific regulator of anthocyanin biosynthesis in pepper (Capsicum annuum)}

2 Jinyoung Byun ${ }^{1}$, Tae-Gun Kim ${ }^{2}$, Joung-Ho Lee ${ }^{1}$, Ning Li ${ }^{3}$, Soyoung Jung ${ }^{1}$, Byoung-Cheorl $3 \mathrm{Kang}^{1 *}$

4

$5 \quad{ }^{1}$ Department of Agriculture, Forestry, and Bioresources, Research Institute of Agriculture and 6 Life Sciences, Plant Genomics Breeding Institute, College of Agriculture and Life Sciences, $7 \quad$ Seoul National University, Seoul, South Korea

$8{ }^{2}$ Interdisciplinary Program in Agricultural Genomics, Department of Agriculture, Forestry, and 9 Bioresources, Research Institute of Agriculture and Life Sciences, Plant Genomics Breeding 10 Institute, College of Agriculture and Life Sciences, Seoul National University, Seoul, South 11 Korea

$12{ }^{3}$ Cash Crops Research Institute, Hubei Academy of Agricultural Sciences, Wuhan City, Hubei 13 Province, 430064, China

14

15

16 * Correspondence:

17 Byoung-Cheorl Kang (bk54@snu.ac.kr)

18 


\section{Abstract}

The key regulatory gene $C a A N 2$ encodes an R2R3 MYB transcription factor that regulates anthocyanin biosynthesis in various tissues in pepper (Capsicum annuum). However, CaAN2 is not expressed in certain pepper accessions showing fruit-specific anthocyanin accumulation. In this study, we identified the novel locus $C a A N 3$ as a regulator of fruit-specific anthocyanin biosynthesis, using an $\mathrm{F}_{2}$ population derived from a hybrid cultivar with purple immature fruits and segregating for $C a A N 3$. We extracted total RNA, assembled two RNA pools according to fruit color, and carried out bulked segregant RNA sequencing. We aligned the raw reads to the pepper reference genome Dempsey and identified 6,672 significant single nucleotide polymorphisms (SNPs) by calculating the $\Delta$ (SNP-index) between the two pools. We then conducted molecular mapping to delimit the target region of CaAN3 to the interval 184.6-186.4 Mbp on chromosome 10. We focused on Dem.v1.00043895, encoding an R2R3 MYB transcription factor, as the strongest candidate gene. Sequence analysis revealed four insertion/deletion polymorphisms in the promoter region of the green CaAN3 allele. We employed virus-induced gene silencing and transient overexpression assays to characterize the function of the candidate gene. When Dem.v1.00043895 was silenced in pepper, anthocyanin accumulation decreased in the pericarp, while the transient overexpression of Dem.v1.00043895 in Nicotiana benthamiana leaves resulted in the accumulation of anthocyanins around the infiltration sites. These results showed that Dem.v1.00043895 is 


\section{Keywords}

40 Anthocyanin, Fine-mapping, Capsicum, R2R3 MYB transcription factor, Transient 41 overexpression, Virus-induced gene silencing.

42

\section{Key Message}

44 The novel gene $C a A N 3$ encodes an R2R3 MYB transcription factor that regulates fruit-specific 45 anthocyanin accumulation. 


\section{Introduction}

Anthocyanins are plant secondary metabolites derived from the flavonoid biosynthesis pathway (Koes et al. 2005; Tanaka et al. 2008). They are among the most abundant pigments found in flowers and fruits, imparting red, blue, and purple coloration. Anthocyanins exert core functions in plants such as attracting pollinators and protecting against biotic and abiotic stresses (de Pascual-Teresa et al. 2010; Jimenez-Garcia et al. 2013). Anthocyanins offer benefits for human health, including anti-inflammatory and anti-carcinogenic properties, as well as the potential to prevent cardiovascular disease and to control obesity or diabetes (Cassidy et al. 2011; He \& Monica Giusti 2010; Khoo et al. 2017; Lin et al. 2017). Since anthocyanins have both aesthetic value and health benefits, breeding cultivars of various crops with increased anthocyanin contents has become a priority (Allan \& Espley 2018).

The anthocyanin biosynthesis pathway has been described in multiple horticultural crops, as well as in the model plants Arabidopsis and petunia (Jaakola 2013; Liu et al. 2018; Pelletier et al. 1997; Tsukaya et al. 1991). It is a branch of the flavonoid biosynthesis pathway and consists of two types of gene: structural genes that encode the enzymes directly participating in anthocyanin biosynthesis, and regulatory genes that regulate the expression of the structural genes (Gonzali et al. 2009). Structural genes are further classified into early biosynthetic genes (EBGs) that synthesize dihydroflavonols, and late biosynthetic genes (LBGs) that catalyze the conversion of leucoanthocyanidins to anthocyanidins (Dubos et al. 2010; Petroni \& Tonelli 2011).

The activation of anthocyanin structural genes is coordinated, and transcription factors (TFs) that directly regulate their expression have been identified in several species (Jaakola 2013). The core of the transcriptional regulation of anthocyanin structural genes relies on the interaction of a DNA-binding R2R3 MYB TF, with a MYC-like basic helix-loop-helix (bHLH) and WD40-repeat proteins (Koes et al. 2005), forming a MYB-bHLH-WD40 (MBW) complex. 
71 The MYB TF is the most crucial component of this complex and can induce anthocyanin 72 accumulation by itself (Hichri et al. 2010; Kiferle et al. 2015; Spelt et al. 2000; Stracke et al. 73 2007).

The Solanaceae family includes widely cultivated horticultural crops such as tomato (Solanum lycopersicum), eggplant (Solanum melongena), potato (Solanum tuberosum), and pepper (Capsicum annuum). Several crop species of the Solanaceae accumulate anthocyanins (Dhar et al. 2015). Due to the commercial importance of Solanaceous crops, substantial work has explored the regulatory mechanisms behind anthocyanin accumulation (Liu et al. 2018), mainly in edible parts such as fruits or tubers. In tomato, SlANT1 and SlAN2 encode R2R3 MYB activators, causing anthocyanin accumulation in vegetative tissues and fruits (Povero et al. 2011; 81 Schreiber et al. 2012). SlAN2-like, encoding another R2R3 MYB TF whose expression is driven by a fruit-specific promoter, acts as a master regulator in anthocyanin biosynthesis, activating the transcription of both structural and regulatory genes (Sun et al. 2019). In eggplant, the functional R2R3 MYB genes $S m M Y B 1$ and $S m M Y B c$ induce the expression of structural genes and lead to the accumulation of anthocyanins in fruits (Gisbert et al. 2016; Stommel \& Dumm 2015; Zhang et al. 2014). In potato, StAN1, StMYBA1, and StMYB113 encode R2R3 MYB TFs that activate anthocyanin biosynthesis and are highly expressed in purple tubers; their expression levels are positively correlated with the transcription levels of structural genes and with anthocyanin concentration (Liu et al. 2016; Strygina et al. 2019). examples, CaAN2 is a R2R3 MYB TF that regulates anthocyanin biosynthesis (Borovsky et al. 2004). The accumulation of anthocyanins is associated with the insertion of a non-long terminal repeat (LTR) retrotransposon into the CaAN2 promoter region. Various tissues including fruits (only at the immature stage) and flowers show purple pigmentation when plants carry a functional $C a A N 2$ allele. In the absence of transcription from the structural genes, immature 
fruits remain green (Jung et al. 2019; Ohno et al. 2020). However, the alleles at CaAN2 fail to

97 fully explain all instances of purple pigmentation in pepper fruits, as certain pepper accessions carrying a non-functional CaAN2 allele still show full purple pigmentation specifically in immature fruits (Jung 2019). By contrast, other accessions with a functional CaAN2 allele exhibit purple pigmentation in flowers, leaves, and fruits.

Bulked segregant analysis (BSA) can be used to identify markers linked to any specific gene or genomic region using two pools of DNA samples. Each pool contains individuals that share an identical target trait or genomic region but segregate independently at all other genomic regions (Michelmore et al. 1991). Bulked segregant RNA sequencing (BSR-seq) is a modified BSA technique that employs RNA instead of DNA, making it possible to efficiently isolate genes even in populations for which no polymorphic markers have been previously identified (Liu et al. 2012). Transcriptome deep sequencing (RNA-seq) is a widely adopted application of next-generation sequencing technologies and allows the comparative quantification of gene expression based on a phenotype of interest (Marioni et al. 2008). RNA-seq can inform on variation in coding regions such as single nucleotide polymorphisms (SNPs), which can also be used as genetic markers (Chepelev et al. 2009).

In this study, we identified the novel locus $C a A N 3$ regulating fruit-specific anthocyanin accumulation using BSR-seq. CaAN3 was previously proposed to regulate fruit-specific anthocyanin biosynthesis (Jung 2019). We previously developed a segregating $F_{2}$ population by crossing two pepper accessions with the non-functional CaAN2 allele, Capsicum annuum 'MAB1' with green immature fruits and $C$. annuum 'MAB2' with fruit-specific purple pigmentation. We observed a 3:1 segregation ratio for purple fruits, indicating that $\operatorname{CaAN3}$ is a single dominant locus. Genetic mapping suggested that CaAN3 is located on chromosome 10, but fine-mapping was not possible due to the large size of a region with no recombination in the mapping interval (Jung 2019). To fine-map CaAN3, we developed an $\mathrm{F}_{2}$ population from a 
121 hybrid bell pepper cultivar with a non-functional CaAN2 allele and with purple pigmentation

122 in fruits. The $F_{2}$ population segregated for purple and green immature fruits, allowing mapping

123 of the responsible gene. Here, we report on the fine-mapping and identification of the CaAN3

124 locus. We validated the identity of the candidate gene by conducting virus-induced gene

125 silencing (VIGS) and transient overexpression. Finally, we explored the expression mechanism

126 of $C a A N 3$ using diverse pepper accessions with purple pigmentation in fruits and/or flowers. 


\section{Materials and methods}

\section{Plant materials}

The two C. annuum accessions MAB2 and MAB1 were obtained from Asia Seed Co., Ltd. (Incheon, Korea) and used as controls for phenotypic and genotypic analyses. MAB2 has purple immature fruits, but green leaves and stems, while MAB1 has green immature fruits, leaves, and stems (Fig. 1a). The fruit-specific purple pigmentation line MAB2 was used in subsequent experiments after the candidate gene was identified. To map the CaAN3 locus, the purple hybrid bell pepper cultivar 'Salad Piment Purple' from Takii Seed Co., Ltd. (Kyoto, Japan) was purchased from the seed market to generate a segregating $F_{2}$ population. An $F_{2}$ population of 243 individuals was used for BSR-seq analysis. In addition, 13 pepper accessions obtained from the National Institute of Agricultural Science (Wanju, Korea) were used to validate the identity of CaAN3.

\section{Nucleic acid extraction}

Genomic DNA was extracted from fresh young leaves by the cetyltrimethyl-ammonium bromide method (Lee et al. 2017). The extracted genomic DNA was dissolved in $1 \times$ Tris-HCl EDTA buffer and then diluted to a concentration of $50 \mathrm{ng} / \mu \mathrm{L}$ with triple-distilled water. Pericarp tissues of immature fruits were used for BSR-seq and expression analyses. Total RNA was extracted from pericarp from immature fruits using the MG RNAzol Kit (MGmed, Seoul, Korea) according to the manufacturer's instructions.

\section{BSR-seq}

An equal amount of RNA was sampled from each of 18 purple and 18 green fruits derived from the $\mathrm{F}_{2}$ population and pooled to make three pools of samples from six individuals per fruit color. The TruSeq Stranded mRNA LT Sample Prep Kit (Illumina, San Diego, CA, USA) was 
used to construct RNA-seq libraries; RNA-seq was performed at Macrogen (Seoul, Korea).

154 After removing adaptors and low-quality reads, raw reads were aligned to the pepper Dempsey v1.0 reference genome (unpublished), utilizing STAR version 2.7.5a (Dobin et al. 2013). Then, the alignments from purple and green RNA pools were analyzed using a quantitative trait locus (QTL) sequencing analysis pipeline (Takagi et al. 2013). SNPs were extracted from the alignment files of the two sets of pools using Samtools. SNPs were filtered and plotted using internal Perl and R scripts of the QTL-seq pipeline. The SNP-index value was computed for each pool as the number of aligned reads to the reference genome. The $\Delta(\mathrm{SNP}$-index $)$ value was defined as the difference between the SNP-indices of the purple and green RNA pools.

\section{Development of a molecular marker for $\mathrm{CaAN3}$}

The previously delimited CaAN3 target region in CM334 reference genome (Jung 2019) was used for further marker development. Based on the SNPs identified by BSR-seq, markers for high-resolution melting (HRM) were developed with an amplicon size of 100-300 bp, to detect polymorphisms in PCR amplicons. Three primers for the sequence-characterized amplified region (SCAR) marker were developed to amplify the CaAN3 promoter region spanning the insertion/deletion (InDel) polymorphism between purple and green alleles. PCR primers were designed with Primer3 (http://web.bioneer.co.kr/cgibin/primer/primer3.cgi).

HRM markers were mainly used for fine-mapping of $\mathrm{CaAN3}$, and the SCAR marker was used to genotype various pepper accessions. Primers used as molecular markers are listed in Table S1.

\section{HRM analysis}

HRM markers were developed based on the BSR-seq results to test for polymorphisms in

177 the developed markers across the $F_{2}$ population. HRM markers were used to genotype $F_{2}$ 
178 individuals on a Rotor-Gene 6000 real-time PCR thermocycler (Corbett Research, Sydney,

179 Australia). Quantitative PCR (qPCR) was performed in reactions containing $2.5 \mu \mathrm{L} 10 \times \mathrm{HiPi}$ 180 reaction buffer (Elpis Biotech, Daejeon, Korea), $2 \mu \mathrm{L} 10 \mathrm{mM}$ dNTPs, $0.5 \mu \mathrm{L}$ each 10-pmol

181 primers, $2 \mu \mathrm{L} 50 \mathrm{ng} / \mu \mathrm{L}$ genomic DNA, $0.3 \mu \mathrm{L}$ Taq polymerase and sterile distilled $\mathrm{H}_{2} \mathrm{O}$ up to

182

183

184

185

186

187

188

189

190

191

192

193

194

195

196

197

198

199

200

201

202 $20 \mu \mathrm{L}$. qPCR reactions consisted of 55 cycles of denaturation at $95^{\circ} \mathrm{C}$ for $30 \mathrm{~s}$, annealing at $58^{\circ} \mathrm{C}$ for $30 \mathrm{~s}$, and extension at $72^{\circ} \mathrm{C}$ for $30 \mathrm{~s}$. After the PCR, HRM analysis was carried out with increasing temperature of $0.1^{\circ} \mathrm{C}$ every min from $65^{\circ} \mathrm{C}$ to $95^{\circ} \mathrm{C}$.

\section{Construction of VIGS vectors}

The pTRV2-LIC vectors were constructed using the ligation independent cloning (LIC) method as previously described (Kim et al. 2017). Partial coding sequences (200-400 bp) of the CaAN3 candidate gene were amplified with LIC adapter primers. The resulting purified PCR amplicon was treated with T4 DNA polymerase (Enzymatics, Beverly, MA, USA) with $1 \times$ blue buffer and $10 \mathrm{mM}$ dATP. The pTRV2-LIC vector was digested with PstI and treated with T4 DNA polymerase in $1 \times$ buffer and $10 \mathrm{mM}$ dTTP. T4 DNA polymerase-treated mixtures were incubated at $22^{\circ} \mathrm{C}$ for $30 \mathrm{~min}$, followed by $75^{\circ} \mathrm{C}$ for $20 \mathrm{~min}$. The two reaction products were then mixed in a 1:3 (vector:insert) ratio. For ligation, the mixture was incubated at room temperature for $30 \mathrm{~min}$, then transformed into Trans $5 \alpha$ competent cell (TransGen Biotech, Beijing, China). Plasmids were extracted using AccuPrep ${ }^{\circledR}$ Plasmid Mini Extraction Kit (Bioneer) and sequenced (Macrogen). Plasmids with complete sequences were introduced into Agrobacterium (Agrobacterium tumefaciens) strain GV3101 by electroporation. pTRV2::PDS and pTRV2::GFP were kindly provided by Prof. Doil Choi (Seoul National University). Primers used for the VIGS study are listed in Table S1.

\section{Agrobacterium infiltration}


Agrobacterium carrying pTRV1, pTRV2::PDS, pTRV2::GFP, and pTRV2::CaAN3 were

204

205

206

207

208

209

210

\section{1}

212

213

214

215

216

217

218

219

220

221

222

223

224

225

226

227

grown at $28^{\circ} \mathrm{C}$ for $2 \mathrm{~d}$. Agrobacterium overnight cultures $(5 \mathrm{~mL})$ were pelleted by centrifugation and resuspended in $10 \mathrm{mM}$ 2-(N-morpholino) ethanesulfonic acid buffer (pH 6.0), $10 \mathrm{mM}$

$\mathrm{MgCl}_{2}$, and $200 \mu \mathrm{M}$ acetosyringone, at a final OD at $600 \mathrm{~nm}$ of 0.6. pTRV1 and pTRV2 constructs were mixed in a 1:1 ratio. After the cell suspensions were incubated at room temperature for $3 \mathrm{~h}$, the constructs were infiltrated into the first and second foliage leaves. The infiltrated plants were then grown in a chamber at $23^{\circ} \mathrm{C}$ with a $16-\mathrm{h}$ light/8-h dark photoperiod.

\section{Transient overexpression in Nicotiana benthamiana leaves}

The coding sequences for CaAN3 and GFP (as control) were cloned into pCAMBIA2300LIC vector harboring the cauliflower mosaic virus $35 \mathrm{~S}$ promoter. The constructs were transformed into Agrobacterium strain GV3101 by electroporation. Agrobacterium infiltrations were performed as above. The cell mixture was infiltrated into young $N$. benthamiana leaves and anthocyanin accumulation was determined at 7-10 d after infiltration. Primers used for vector construction are listed in Table S1.

\section{Total anthocyanin quantification}

Anthocyanins in $N$. benthamiana leaves were extracted and quantified as previously described (Mazzucato et al. 2013) with slight modifications. Infiltrated leaf sections were collected and weighted to $0.5 \mathrm{~g}$ each, then transferred into a tube containing $5 \mathrm{~mL}$ anthocyanin extraction solution (1-propanol:HCl:distilled water, 1:1:81, v:v:v). The tubes were boiled in a water bath for 6 min and then incubated overnight in the dark at room temperature. Absorbance was recorded spectrophotometrically at $535 \mathrm{~nm}$ and $650 \mathrm{~nm}$ with a NanoDrop1000 instrument (NanoDrop Technologies, Wilmington, DE, USA). Total anthocyanin contents were quantified as the difference in absorbance at $535 \mathrm{~nm}$ and $650 \mathrm{~nm}$ based and normalized to the fresh weight 
of each sample in grams.

\section{High-performance liquid chromatography (HPLC) analysis of anthocyanidins}

To measure anthocyanidin contents, at least three immature fruits were harvested from each individual plant with two replicates and freeze-dried. Extracts were prepared from $0.1 \mathrm{~g}$ of immature fruit samples. The HPLC analysis was performed using an UltiMate 3000RS liquid chromatography system (Thermo Fisher Scientific, Waltham, MA, USA) equipped with a reversed-phase Waters-XTerra C18 column (Waters Corporation, Milford, MA, USA). Mobile phase A used $0.5 \%$ trifluoro-acetic acid, and phase B used $100 \%$ acetonitrile. The separation conditions for phase B were 0-2 $\min (14 \%), 2-4 \min (17 \%), 4-7 \min (28 \%), 7-10 \min (36 \%)$, 10-12 $\min (60 \%)$, and $12-15 \mathrm{~min}(0 \%)$ with a flow rate of $0.6 \mathrm{~mL} / \mathrm{min}$. As standards for quantification, cyanidin chloride, delphinidin chloride, malvidin chloride, pelargonidin chloride, and peonidin chloride (Extrasynthese, Genay, France) were used, and total anthocyanidin contents were quantified by measuring the absorbance at $520 \mathrm{~nm}$. HPLC was performed at 


\section{Results}

245 Segregation of the purple phenotype in the mapping population

To map the CaAN3 locus, we generated an $\mathrm{F}_{2}$ population derived from self-pollinated

247 plants from the C. annuum hybrid cultivar Salad Piment Purple, which shows the same purple 248 immature fruit coloration as MAB2. The $\mathrm{F}_{2}$ population used for mapping consisted of 243 249 individuals and exhibited a segregation ratio of 2.12:1 (immature purple:immature green), with 250 a $\chi^{2}$ value of 0.011 . This segregation pattern was similar to that seen in the $F_{2}$ population 251 derived from a cross between the cultivars MAB1 and MAB2. All individuals in the mapping 252 population produced mature red fruits (Fig. 1b).

We genotyped $C a A N 2$ in the $\mathrm{F}_{2}$ mapping population, $\mathrm{MAB} 1$, and $\mathrm{MAB} 2$ with a previously developed SCAR marker, which distinguishes CaAN2 alleles based on structural variation in the $C a A N 2$ promoter region. MAB2 carries a non-functional $C a A N 2$ allele but is characterized by fruit-specific anthocyanin biosynthesis. Screening the $F_{2}$ population from Salad Piment Purple showed that all individuals harbor a non-functional CaAN2 allele, as do the MAB1 and MAB2 cultivars (Fig. 1c), indicating that the segregating phenotype is independent from the genotype at $\mathrm{CaAN} 2$.

\section{The $\mathrm{CaAN3}$ locus maps to chromosome 10}

To identify $C a A N 3$, we combined RNA-seq with BSA. We prepared three RNA pools from six individuals for each phenotypic bulk (18 purple and 18 green plants) and sequenced the resulting libraries on the Illumina platform. We obtained an average of 121,311,533 reads per RNA pool by BSR-seq, reaching a total of $33.6 \mathrm{~Gb}$ for the purple pools and $39.9 \mathrm{Gbp}$ for the green pools and a coverage of $748 \times$ (purple samples) and $890 \times$ (green samples). An average of 340 million raw reads mapped to the reference genome Dempsey v1.0, covering 
about $96 \%$ of the predicted coding regions in the genome (Table 1). We identified 311,679 raw SNPs, of which 63,316 remained after filtering out non-polymorphic and low-quality sites. Using these filtered SNPs, we calculated the $\Delta(\mathrm{SNP}$-index $)$ values as the difference between

271

272

273

274

275

276

277

278

279

280

281

282

283

284

285

286

287

288

289

290

291 the two different pools.

To delimit the CaAN3 candidate interval, we selected 6,672 SNPs with $\Delta$ (SNP-index) values higher than the $99 \%$ confidence level, leading to identification of five candidate regions on chromosomes 1,8 , and 10 . We observed the highest peak of $\Delta$ (SNP-index) values on chromosome 10 corresponding to two candidate regions, $0.15-108.8 \mathrm{Mb}$ and $121.7-239.8 \mathrm{Mb}$ (Fig. 2a).

From the BSR-seq analysis, we estimated the physical position of CaAN3 to be within either the interval $0.15-108.8 \mathrm{Mb}$ or the interval $121.7-239.8 \mathrm{Mb}$ on chromosome $10 \mathrm{We}$ genotyped $\mathrm{F}_{2}$ individuals from the mapping population with HRM-10-63 at $62.9 \mathrm{Mb}$ and SWPm_00416 located at $168.1 \mathrm{Mb}$, which revealed recombinants and thus indicated that the candidate region likely lies downstream of $168.1 \mathrm{Mb}$ on chromosome 10 . We used an additional five markers, developed based on the SNP information obtained from BSR-seq, to refine the map position of the $C a A N 3$ locus, leading to a final candidate region spanning the interval 184.6-186.4 Mb on chromosome 10 of the Dempsey v1.0 reference genome (Fig. 2b).

\section{Dem.v1.00043895 is a candidate gene for $\mathrm{CaAN3}$}

Since the $\Delta$ (SNP-index) approach did not reveal an obvious candidate for CaAN3 on chromosome 10, we looked for differentially expressed genes (DEGs) between purple and green pools and identified 2,175 significant DEGs. Gene Ontology (GO) term enrichment analysis showed that these DEGs are enriched in twelve GO terms, including secondary metabolic process and carbohydrate metabolic process in the 'biological process' category; 
transcription factor activity and catalytic activity in 'molecular function'; and extracellular region in 'cellular component' (Fig. S1a). In addition, we detected enrichment for eight Kyoto

294

295

296

297

298

299

300

301

302

303

304

305

306

307

308

309

310

311

312

313

314

315

316

Encyclopedia of Genes and Genomes (KEGG) pathways, four of which were related to anthocyanin biosynthesis such as 'biosynthesis of secondary metabolites', 'metabolic pathways', 'phenylpropanoid biosynthesis', and 'flavonoid biosynthesis' (Fig. S1b). The EBGs $P A L, C 4 H, 4 C L, C H S, C H I$, and $F 3 H$ did not appear to be differentially expressed between purple and green fruits. By contrast, we detected significant differences in the expression levels of the LBGs DFR, $A N S$, and $3 G T$, between purple and green fruits (Fig. S2).

The final candidate region contained 15 annotated genes, of which 8 were not expressed in either purple or green fruits. Three genes, Dem.v1.00043888, Dem.v1.0043915, and Dem.v1.0043916, showed minimal expression levels ranging from 0.01 to $0.41 \log _{2}$ (average FPKM + 1). Another three genes, Dem.v1.00043885, Dem.v1.0043901, and Dem.v1.0043918, exhibited relatively high expression levels but were not differentially expressed between purple and green immature fruits. The final gene, Dem.v1.00043895, which was annotated as encoding a MYB-type transcription factor, was not expressed in green fruits but was highly expressed in purple fruits (Table 2), making Dem.v1.00043895 the strongest candidate gene for CaAN3.

\section{The Dem.v1.00043895 promoter region exhibits structural variation}

To explore possible sequence variation at the Dem.v1.00043895 locus between purple and green genotypes, we randomly selected individuals from the Salad Piment Purple $F_{2}$ population and sequenced the Dem.v1.00043895 promoter and coding regions. As controls, we also sequenced Dem.v1.00043895 from genomic DNA extracted from the leaves of $F_{2}$ individuals homozygous for linked markers as well as the MAB2 (purple immature fruit) and MAB1 (green immature fruit) cultivars. We determined that the promoter region is identical in $\mathrm{F}_{2}$ individuals with the purple allele and MAB2. Likewise, $\mathrm{F}_{2}$ individuals homozygous for the green allele and 
MAB1 had identical promoter structures.

We detected several structural variants in the promoter region between purple and green 319 CaAN3 alleles: a 4-bp insertion at nucleotide $-1,428$ (+1 being the ATG), a 7-bp insertion at nucleotide $-1,069$, a 35 -bp insertion at nucleotide -887 , and a 15 -bp deletion at nucleotide 157 in the promoter region of the green CaAN3 allele (Fig. 3a). We also identified an A-to-D change between the purple and green predicted proteins at amino acid residue 43 . We noticed another amino acid change (at residue 211), but the genotype did not correlate with fruit phenotype (Fig. 3b). Based on these polymorphisms in relation to the measured expression pattern, we hypothesized that variation in the promoter region might be responsible for the loss of Dem.v1.00043895 expression in green fruits, while the purple CaAN3 allele is functional and expressed in purple immature fruits.

\section{Dem.v1.00043895 is specifically expressed in immature fruits}

To investigate the expression pattern of the candidate gene Dem.v1.00043895, we collected MAB2 fruits over the course of their development (Fig. S3a) and performed RT-qPCR. The candidate gene was most highly expressed when purple pigments accumulate throughout the fruit, in the very early stages of fruit development. As the fruit matured and the purple pigmentation disappeared, the expression levels of the gene gradually decreased. After $40 \mathrm{~d}$ post anthesis (DPA), when fruits lost most of their purple pigmentation and took on their mature red color, the gene showed almost no detectable expression (Fig. S3b). We measured anthocyanidin concentrations by HPLC analysis over the same developmental time course, which revealed a similar pattern that correlates with pericarp color. Anthocyanidin contents were highest in the earliest stages of fruit growth before gradually decreasing as fruits developed. Of the five anthocyanidins (cyanidin, delphinidin, malvidin, pelargonidin, and

341 peonidin) detected by HPLC analysis, delphinidin represented over 99\% of the total 
anthocyanidin contents (Fig. S3c). Dem.v1.00043895 was specifically expressed in immature

343 fruits at 20 DPA but was expressed to much lower levels in leaves, stems, and flowers, as 344 expected for the CaAN3 candidate gene (Fig. S3d).

\section{Silencing Dem.v1.00043895 blocks purple pigmentation in pericarp}

To determine whether Dem.v1.00043895 is CaAN3, we silenced the gene via TRVmediated VIGS. To this end, we cloned a specific fragment from the Dem.v1.00043895 coding sequence into the silencing vector TRV2. Agrobacterium cultures carrying pTRV2::GFP and pTRV2::PDS were used as negative and positive controls, respectively. We infiltrated leaves from the $C$. annuиm cultivar MAB2 with purple immature fruits; infiltration with pTRV2::GFP did not alter fruit pigmentation, while plants infiltrated with pTRV2::PDS developed bleaching in leaves, indicating that Phytoene desaturase $(P D S)$ is properly silenced. Plants infiltrated with pTRV2::GFP or pTRV::PDS produced fully purple fruits that are undistinguishable from those of the parental cultivar MAB2. In sharp contrast, plants infiltrated with the TRV2 construct targeting Dem.v1.00043895 showed alterations in fruit pigmentation. Although the phenotype of infiltrated plants showed slight differences, most infiltrated plants were characterized by fruits lacking accumulation of anthocyanins. In some plants, fruits remained green throughout their immature stages. Other plants showed pericarp with purple and green sectors with clearly defined margins between the two colors (Fig. 4a). The green sectors of the pericarp never turned purple as fruit development progressed. HPLC analysis from several immature and mature fruits from different plants confirmed that delphinidins do not accumulate in the regions devoid of purple pigmentation (Fig. 4b).

We investigated expression levels of anthocyanin biosynthesis genes in control and silenced fruits: when Dem.v1.00043895 was silenced, we observed a downregulation of 
negative control. Transcripts of both EBGs and LBGs accumulated to lower levels in Dem.v1.00043895-silenced plants. However, the EBGs $4 C L$ and $F 3 H$ were expressed to comparable levels in Dem.v1.00043895-silenced and control fruits (Fig. 4c). LBGs showed clearer differences, with the downregulation of $D F R, F 3$ '5' $H$, and ANS in Dem.v1.00043895silenced plants. In particular, $D F R$ and $F 3^{\prime} 5^{\prime} H$ transcripts were barely detectable in may directly regulate LBG expression in the anthocyanin biosynthetic pathway.

Overexpression of Dem.v1.00043895 induces the accumulation of anthocyanin in $N$.

\section{benthamiana leaves}

To further explore the role of Dem.v1.00043895 in anthocyanin biosynthesis, we transiently overexpressed the gene in $N$. benthamiana leaves by cloning the Dem.v1.00043895 coding sequence in the pCAMBIA2300 vector under the control of the $35 \mathrm{~S}$ promoter (Fig. S4a). We also infiltrated $N$. benthamiana leaves with Agrobacterium harboring the pCAMBIA2300:GFP construct as a negative control. About $10 \mathrm{~d}$ after infiltration, we noticed an alteration of color around the infiltration sites when overexpressing Dem.v1.00043895, while leaves infiltrated with pCAMBIA2300:GFP showed no change in color (Fig. S4b). We confirmed this visual observation by quantifying anthocyanin accumulation (Mazzucato et al. 2013): extracts from leaves overexpressing Dem.v1.00043895 were purple with anthocyanin contents of 7.4-25.6 per $\mathrm{g}$ fresh weight, based on the difference in absorbance at $535 \mathrm{~nm}$ and at $650 \mathrm{~nm}$, while extracts from non-infiltrated and negative control plants were slightly green with anthocyanin contents of 1.3-2.2 per g fresh weight (Fig. S4c). 
We hypothesized that Dem.v1.00043895 is a master regulator of fruit-specific anthocyanin

393

394

395

396

397

398

399

400

401

402

403

404

405

406

407

408

409

410

411

412

413

414

415

416

biosynthesis and that structural variation in its promoter region determines the functionality of the gene. To test this possibility, we genotyped and phenotyped several pepper accessions with purple or green immature fruit, alongside MAB1 and MAB2 as controls. We classified the 24 different pepper accessions characterized here into four distinct phenotypic groups: Group I with small purple fruits and purple flowers (eight accessions); Group II with purple fruits and white flowers (fruit-specific pigmentation; four accessions, including MAB2); Group III with pale purple fruits together with a yellow background and white flowers (four accessions); and Group IV with green immature fruits and white flowers (eight accessions, including MAB1) (Fig. S5). Detailed phenotypes of the 24 pepper accessions including leaf and stem color are summarized in Table S2.

We also determined the expression levels of the candidate gene for CaAN3 (Dem.v1.00043895) and CaAN2 in these 24 accessions, revealing several trends. First, CaAN2 expression levels showed a positive correlation with Group-I accessions with purple fruit and flowers. Second, CaAN3 was only expressed in Group-II accessions with purple fruit and white flowers, in agreement with Dem.v1.00043895 being CaAN3. The four accessions from Group III with yellow immature skin color with pale purple pigmentation showed little CaAN2 expression and almost no CaAN3 expression. Finally, Group-IV accessions with green immature fruit had almost no detectable expression of either CaAN2 or CaAN3 (Fig. 5a,b). CaAN2 was expressed only in pepper accessions with purple flowers. Three of these accessions also showed purple pigmentation in leaves (Table S2).

\section{Structural variation in the promoter region is not directly related to $\mathrm{CaAN} 3$ expression}

We developed a SCAR marker set targeting the deletion found in the promoter region (Table S3) to genotype the 24 accessions phenotyped above. The MAB1 accession, which 
417 carries the same green CaAN3 allele as Salad Piment Purple, showed the expected 524-bp

418 amplicon. However, most of the other lines yielded a 1,188-bp PCR product (the same size as 419 in MAB2) regardless of their fruit or flower pigmentation (Fig. S6). The CaAN3 promoter 420 region was identical between the two pepper accessions 'IT218962' and 'KC00134' (with 421 purple pigmentation for both fruit and flowers) and MAB2 (data not shown), although MAB2 422 only showed expression of CaAN2. The IT158637 and IT229203 accessions with pale purple 423 pigmentation in fruits produced relatively weak or no amplification despite several attempts. 424 425 


\section{Discussion}

In this study, we identified CaAN3 as encoding an R2R3 MYB TF that regulates fruitspecific anthocyanin accumulation in pepper. We propose that the likely candidate gene for CaAN3 is Dem.v1.00043895 in the Dempsey v1.0 reference genome and is located at $185.2 \mathrm{Mb}$ on chromosome 10. Plants derived from the $F_{2}$ mapping population and homozygous for either the purple or green $C a A N 3$ allele exhibited distinct structural variants in the CaAN3 promoter region. Furthermore, we confirmed that silencing CaAN3 impairs the biosynthesis of fruitspecific anthocyanins in pepper, while overexpression of CaAN3 was sufficient to induce the accumulation of anthocyanins in N. benthamiana leaves.

R2R3 MYB TFs are well-known regulatory factors that activate the transcription of structural genes in the anthocyanin biosynthesis pathway in various plants (Jaakola 2013). Several R2R3 MYB TFs act as anthocyanin activators in Solanaceous plants such as tomato, pepper, eggplant, and potato (Liu et al. 2018). However, relatively few studies have been conducted in pepper, in which the R2R3 MYB TF CaAN2 positively regulates anthocyanin accumulation in multiple tissues including immature fruits, flowers and leaves (Borovsky et al. 2004; Jung et al. 2019). The insertion of a non-LTR retrotransposon into the CaAN2 promoter region determines the functionality of the CaAN2 allele. The genes $F 3 H, D F R, A N S$, and Anthocyanidin 3-O-glucosyltransferase (UFGT) were expressed to lower levels in plants with non-functional CaAN2 alleles, suggesting that CaAN2 regulates several LBGs from the anthocyanin biosynthesis pathway (Jung et al. 2019). However, additional genetic factor(s) likely contribute to the regulation of anthocyanin biosynthesis besides CaAN2, especially in accessions with fruit-specific anthocyanin accumulation, as several pepper have purple fruits despite carrying a non-functional CaAN2 allele.

We undertook a BSR-seq analysis to identify the novel locus CaAN3 that regulates fruitspecific anthocyanin biosynthesis by comparing expression levels between plants with purple 
or green fruits at the breaker stage and developed molecular markers to narrow down the 452 candidate region encompassing CaAN3, which affected the expression of several LBGs. 453 Sequence analysis of the strongest candidate locus revealed several InDel polymorphisms in 454 the promoter of the presumed green allele that might be associated with the loss of CaAN3 455 functionality.

We performed VIGS in pepper and transient overexpression in $N$. benthamiana leaves to 457 validate the role of the candidate gene Dem.v1.00043895 in regulating the expression of anthocyanin biosynthesis genes. Fruits from silenced plants lost purple pigments at the immature stage and even produced some green immature fruits similar to those seen in other pepper accessions with green fruit. Anthocyanin concentrations in pericarps decreased correspondingly in the silenced fruits. Conversely, overexpression of the candidate gene caused purple pigmentation of $N$. benthamiana leaves, confirming that anthocyanins accumulate upon overexpression of $\mathrm{CaAN3}$.

We developed a SCAR marker set based on the promoter variants detected between plants with green and purple fruits to genotype 24 pepper accessions. Most accessions, including those producing green immature fruits, exhibited the same genotype as the accession MAB2 with 467 purple fruit and thus carrying the functional allele, contradictory to our hypothesis, although we did observe a positive correlation between expression of the CaAN3 candidate gene and anthocyanin accumulation in immature fruit. In particular, the promoter regions from the $470 \mathrm{KC} 00134$ and IT218962 accessions, which express CaAN2 but not CaAN3, were identical to 471 that of MAB2 with purple immature fruit. Therefore, we conclude that there is no direct 472 correlation between the fruit-specific accumulation of anthocyanins and the structural variation 473 in the CaAN3 promoter region.

474 Although this study successfully identified a gene that can exert the function expected for $475 \mathrm{CaAN3}$, further studies will be needed to better understand how it is regulated, such as an 
476 investigation of the underlying transcriptional network. Based on the examples of 477 transcriptional networks in tomato, we hypothesize that another genetic factor may be involved 478 in CaAN3-mediated anthocyanin biosynthesis. In tomato, four genes encoding R2R3 MYB TFs 479 (SlAN2, SlANT1, SlAN1, and SlAN2-like) are clustered on chromosome 10. SlAN2 is mainly expressed in stems, leaves, and flowers rather than immature fruits, whereas SlAN2-like is specifically and strongly expressed in immature fruits (Kiferle et al. 2015; Sun et al. 2019). However, overexpression of either SIAN2 or SlAN2-like is sufficient to induce anthocyanin accumulation in several tissues such as pericarp and stamens. Phylogenic analysis showed that 484 SIAN2 regulating anthocyanin mainly in vegetative tissues clusters with the fruit-specific 485 regulator CaAN3, while the fruit-specific regulator SlAN2-like groups with CaAN2 (Fig. 6). 486 The functional differences between these TFs from tomato and pepper may therefore have 487 occurred following the divergence of these two members of the Solanaceae (Quattrocchio et al. 488 1998).

Unfortunately, correlation or hierarchy between the two tomato R2R3 MYB TFs has not been studied in detail, although their individual functions are well characterized. The anthocyanin biosynthesis repressor SIMYBATV, a R3 MYB TF, competes with SlAN2-like for interaction with SIAN1, a bHLH TF. It will be necessary to test whether a homologous repressor exists in pepper with a similar function and how the gene affects the expression of

494 CaAN2 or CaAN3. A genetic approach may also be undertaken by crossing two pepper 495 accessions: one with functional $C a A N 2$ and $C a A N 3$ alleles but that only expresses $C a A N 2$, and 496 another accession with a non-functional CaAN2 allele and a functional CaAN3 allele. The 497 expression of $C a A N 2$ and $C a A N 3$ in the resulting $\mathrm{F}_{1}$ and $\mathrm{F}_{2}$ progeny will inform on the genetic 498 architecture of anthocyanin accumulation.

499 In conclusion, this study identified a new regulatory factor involved in anthocyanin 500 biosynthesis in pepper and provided a hypothesis for the underlying regulatory network. Our 
501 results add to the growing body of work aimed at understanding the anthocyanin transcriptional 502 network in Solanaceous crops including pepper, with the goal of allowing the engineering of a 503 pepper cultivar with high contents of anthocyanins beneficial to human health. 
504 Supplementary Information The online version contains supplementary material available at 505 xxx.

507 Funding This work was supported by Korea Institute of Planning and Evaluation for 508 Technology in Food, Agriculture and Forestry (IPET) through Technology

509 Commercialization Support Program, funded by Ministry of Agriculture, Food and Rural 510 Affairs (MAFRA) (821012-03). This work was carried out with the support of "Cooperative

511 Research Program for Agriculture Science and Technology Development (Project No.

512 PJ015881)" Rural Development Administration, Republic of Korea.

514 Competing Interests The authors have no relevant financial or non-financial interests to 515 disclose.

517 Authors' Contributions JB participated in population generation, phenotype analysis, 518 development of markers, gene functional studies and manuscript writing. NL and TGK 519 participated in the fine-mapping of the gene. JHL participated in the BSR-seq analysis. SYJ 520 participated in initial experiment. BCK participated in the design of the study and editing of 521 the manuscript.

523 Data Availability Transcriptome analysis of immature fruit color in Capsicum annuum was 524 deposited into Sequence read archive (SRA) database under the accession numbers of 525 SAMN25289192 and SAMN25289193, respectively.

527 Acknowledgements This work was supported by Korea Institute of Planning and Evaluation 528 for Technology in Food, Agriculture and Forestry (IPET) through Technology 
529 Commercialization Support Program, funded by Ministry of Agriculture, Food and Rural 530 Affairs (MAFRA) (821012-03). This work was carried out with the support of "Cooperative 531 Research Program for Agriculture Science and Technology Development (Project No. 532 PJ015881)" Rural Development Administration, Republic of Korea.

533 


\section{References}

535 Allan AC, Espley RV (2018) MYBs Drive Novel Consumer Traits in Fruits and Vegetables. Trends Plant Sci 23:693-705

Borovsky Y, Oren-Shamir M, Ovadia R, De Jong W, Paran I (2004) The A locus that controls anthocyanin accumulation in pepper encodes a MYB transcription factor homologous to Anthocyanin2 of petunia. Theor Appl Genet 109:23-29

Cassidy A, O’Reilly ÉJ, Kay C, Sampson L, Franz M, Forman JP, Curhan G, Rimm EB (2011) Habitual intake of flavonoid subclasses and incident hypertension in adults. Am J Clin Nutr 93:338-347

Chepelev I, Wei G, Tang Q, Zhao K (2009) Detection of single nucleotide variations in expressed exons of the human genome using RNA-Seq. Nucleic Acids Res 37:1-8

de Pascual-Teresa S, Moreno DA, García-Viguera C (2010) Flavanols and anthocyanins in cardiovascular health: A review of current evidence. Int J Mol Sci 11:1679-1703

Dhar MK, Sharma R, Koul A, Kaul S (2015) Development of fruit color in Solanaceae: A story of two biosynthetic pathways. Brief Funct Genomics 14:199-212 TR (2013) STAR: Ultrafast universal RNA-Seq aligner. Bioinformatics 29:15-21

Dubos C, Stracke R, Grotewold E, Weisshaar B, Martin C, Lepiniec L (2010) MYB transcription factors in Arabidopsis. Trends Plant Sci 15:573-581

Gisbert C, Dumm JM, Prohens J, Vilanova S, Stommel JR (2016) A spontaneous eggplant (Solanum melongena L.) color mutant conditions anthocyanin-free fruit pigmentation. 
Gonzali S, Mazzucato A, Perata P (2009) Purple as a tomato: Towards high anthocyanin tomatoes. Trends Plant Sci 14:237-241

He J, Monica Giusti M (2010) Anthocyanins: Natural colorants with health-promoting properties. Annu Rev Food Sci Technol 1:163-187

\section{0}

561

562

563

564

565

566

567

568

569

570

571

572

573

574

575

Hichri I, Heppel SC, Pillet J, Léon C, Czemmel S, Delrot S, Lauvergeat V, Bogs J (2010) The basic helix-loop-helix transcription factor MYC1 is involved in the regulation of the flavonoid biosynthesis pathway in grapevine. Mol Plant 3:509-523

Jaakola L (2013) New insights into the regulation of anthocyanin biosynthesis in fruits. Trends Plant Sci. 18:477-483

Jimenez-Garcia SN, Guevara-Gonzalez RG, Miranda-Lopez R, Feregrino-Perez AA, TorresPacheco I, Vazquez-Cruz MA (2013) Functional properties and quality characteristics of bioactive compounds in berries: Biochemistry, biotechnology, and genomics. Food Res. Int. 54:1195-1207

Jung S (2019) Identification of genetic factors controlling anthocyanin biosynthesis in Capsicum апnиит. Dissertation, Seoul National University.

Jung S, Venkatesh J, Kang MY, Kwon JK, Kang BC (2019) A non-LTR retrotransposon activates anthocyanin biosynthesis by regulating a MYB transcription factor in Capsicum аппиит. Plant Sci 287:110181

Khoo HE, Azlan A, Tang ST, Lim SM (2017) Anthocyanidins and anthocyanins: Colored pigments as food, pharmaceutical ingredients, and the potential health benefits. Food Nutr 
577 Kiferle C, Fantini E, Bassolino L, Povero G, Spelt C, Buti S, Giuliano G, Quattrocchio F, Koes 578 R, Perata P, Gonzali S (2015) Tomato R2R3-MYB proteins SlANT1 and SlAN2: Same 579 protein activity, different roles. PLoS One 10:1-20

580 Kim J, Park M, Jeong ES, Lee JM, Choi D (2017) Harnessing anthocyanin-rich fruit: A visible 581 reporter for tracing virus-induced gene silencing in pepper fruit. Plant Methods 13:1-10

582 Koes R, Verweij W, Quattrocchio F (2005) Flavonoids: A colorful model for the regulation and 583 evolution of biochemical pathways. Trends Plant Sci 10:236-242

Lee JH, An JT, Siddique MI, Han K, Choi S, Kwon JK, Kang BC (2017) Identification and 585 molecular genetic mapping of Chili veinal mottle virus (ChiVMV) resistance genes in pepper (Capsicum annuum). Mol Breed 37:1-10

Lin BW, Gong CC, Song HF, Cui YY (2017) Effects of anthocyanins on the prevention and treatment of cancer. Br J Pharmacol 174:1226-1243

Liu S, Yeh CT, Tang HM, Nettleton D, Schnable PS (2012) Gene mapping via bulked segregant RNA-Seq (BSR-Seq). PLoS One 7:1-8

Liu Y, Lin-Wang K, Espley R V., Wang L, Yang H, Yu B, Dare A, Varkonyi-Gasic E, Wang J, Zhang J, Wang D, Allan AC (2016) Functional diversification of the potato R2R3 MYB anthocyanin activators AN1, MYBA1, and MYB113 and their interaction with basic helixloop-helix cofactors. J Exp Bot 67:2159-2176 biosynthesis and degradation mechanisms in Solanaceous vegetables: A review. Front Chem 
Marioni JC, Mason CE, Mane SM, Stephens M, Gilad Y (2008) RNA-Seq: An assessment of technical reproducibility and comparison with gene expression arrays. Genome Res

600 18:1509-1517

601

602

603

604

605

606

607

608

609

610

611

612

613

614

615

616

617

Mazzucato A, Willems D, Bernini R, Picarella ME, Santangelo E, Ruiu F, Tilesi F, Soressi GP (2013) Novel phenotypes related to the breeding of purple-fruited tomatoes and effect of peel extracts on human cancer cell proliferation. Plant Physiol Biochem 72:125-133

Michelmore RW, Paran I, Kesseli R V. (1991) Identification of markers linked to diseaseresistance genes by bulked segregant analysis: A rapid method to detect markers in specific genomic regions by using segregating populations. Proc Natl Acad Sci USA 88:9828-9832

Ohno S, Ueno M, Doi M (2020) Differences in the CaMYBA genome between anthocyaninpigmented cultivars and non-pigmented cultivars in pepper (Capsicum annuиm). Hort $\mathbf{J}$ $89: 30-36$

Pelletier MK, Murrell JR, Shirley BW (1997) Characterization of flavonol synthase and leucoanthocyanidin dioxygenase genes in Arabidopsis (Further evidence for differential regulation of "early" and "late" genes). Plant Physiol 113:1437-1445

Petroni K, Tonelli C (2011) Recent advances on the regulation of anthocyanin synthesis in reproductive organs. Plant Sci 181:219-229

Povero G, Gonzali S, Bassolino L, Mazzucato A, Perata P (2011) Transcriptional analysis in high-anthocyanin tomatoes reveals synergistic effect of Aft and atv genes. J Plant Physiol $168: 270-279$ 
618 Quattrocchio F, Wing JF, van der Woude K, Mol JN, Koes R (1998) Analysis of bHLH and 619 MYB domain proteins: Species-specific regulatory differences are caused by divergent 620 evolution of target anthocyanin genes. Plant J 13:475-488

621 Schmittgen TD, Livak KJ (2008) Analyzing real-time PCR data by the comparative CT method. $622 \quad$ Nat Protoc 3:1101-1108

623 Schreiber G, Reuveni M, Evenor D, Oren-Shamir M, Ovadia R, Sapir-Mir M, Bootbool-Man A, Nahon S, Shlomo H, Chen L, Levin I (2012) ANTHOCYANIN1 from Solanum chilense is more efficient in accumulating anthocyanin metabolites than its Solanum lycopersicum counterpart in association with the ANTHOCYANIN FRUIT phenotype of tomato. Theor Appl Genet 124:295-307

Spelt C, Quattrocchio F, Mol JNM, Koes R (2000) Anthocyaninl of petunia encodes a basic helix-loop-helix protein that directly activates transcription of structural anthocyanin genes.

Stommel JR, Dumm JM (2015) Coordinated regulation of biosynthetic and regulatory genes Plant Cell 12:1619-1631

634 Stracke R, Ishihara H, Huep G, Barsch A, Mehrtens F, Niehaus K, Weisshaar B (2007) 635 Differential regulation of closely related R2R3-MYB transcription factors controls flavonol accumulation in different parts of the Arabidopsis thaliana seedling. Plant J 50:660-677

637 Strygina K V., Kochetov A V., Khlestkina EK (2019) Genetic control of anthocyanin 638 pigmentation of potato tissues. BMC Genet 20:35-43

639 Sun C, Deng L, Du M, Zhao J, Chen Q, Huang T, Jiang H, Li CB, Li C (2019) A transcriptional 

network promotes anthocyanin biosynthesis in tomato flesh. Mol Plant 13:42-58

641 Takagi H, Abe A, Yoshida K, Kosugi S, Natsume S, Mitsuoka C, Uemura A, Utsushi H, Tamiru

642 M, Takuno S, Innan H, Cano LM, Kamoun S, Terauchi R (2013) QTL-Seq: Rapid mapping 643 of quantitative trait loci in rice by whole genome resequencing of DNA from two bulked 644 populations. Plant J 74:174-183

645 Tanaka Y, Sasaki N, Ohmiya A (2008) Biosynthesis of plant pigments: Anthocyanins, betalains 646 and carotenoids. Plant J 54:733-749

647 Tsukaya H, Ohshima T, Naito S, Chino M, Komeda Y (1991) Sugar-dependent expression of 648 the CHS-A Gene for chalcone synthase from petunia in transgenic Arabidopsis. Plant Physiol $649 \quad 97: 1414-1421$

650 Zhang Y, Hu Z, Chu G, Huang C, Tian S, Zhao Z, Chen G (2014) Anthocyanin accumulation 651 and molecular analysis of anthocyanin biosynthesis-associated genes in eggplant (Solanum 652 melongena L.). J Agric Food Chem 62:2906-2912

653 Zhang Z, Li DW, Jin JH, Yin YX, Zhang HX, Chai WG, Gong ZH (2015) VIGS approach 654 reveals the modulation of anthocyanin biosynthetic genes by CaMYB in chili pepper leaves. 655 Front Plant Sci 6:1-10 
657 Table 1. Summary of BSR-seq analysis of the purple and green bulk samples.

\begin{tabular}{lll}
\hline Information & Purple & Green \\
\hline Number of individuals in pools & 18 & 18 \\
Number of raw reads & $332,378,020$ & $395,491,780$ \\
Total size $(\mathrm{Gb})$ & 33.6 & 39.9 \\
Coverage & $\sim 748 \times$ & $\sim 890 \times$ \\
Number of mapped reads & $310,907,661$ & $369,932,886$ \\
Percentage of mapped reads & 96.1 & 96.1 \\
\hline
\end{tabular}

658 
659 Table 2. Annotated genes in the $C a A N 3$ candidate interval on chromosome 10 and their relative 660 gene expression levels.

\begin{tabular}{|c|c|c|c|c|}
\hline \multirow[t]{2}{*}{ Gene } & \multirow{2}{*}{$\begin{array}{c}\text { Physical } \\
\text { location } \\
(\mathrm{Mb})\end{array}$} & \multirow[t]{2}{*}{ Annotation } & \multicolumn{2}{|c|}{$\begin{array}{l}\text { Relative gene expression } \\
\qquad \log _{2}(\text { average FPKM }+1)\end{array}$} \\
\hline & & & Green & Purple \\
\hline DEM.v1.00043883 & 184.6 & $\begin{array}{l}\text { Similar to MYB1: Transcription factor MYB1 } \\
\text { (Actinidia chinensis var. chinensis) }\end{array}$ & 0.00 & 0.00 \\
\hline DEM.v1.00043884 & 184.7 & Protein of unknown function & 0.00 & 0.00 \\
\hline DEM.v1.00043885 & 184.8 & $\begin{array}{l}\text { Heavy metal-associated isoprenylated plant protein } 6 \\
\text { (Arabidopsis thaliana) }\end{array}$ & 6.72 & 6.69 \\
\hline DEM.v1.00043888 & 185.0 & Protein of unknown function & 0.00 & 0.41 \\
\hline DEM.v1.00043895 & 185.2 & $\begin{array}{l}\text { Similar to MYB1: Transcription factor MYB1 } \\
\text { (Actinidia chinensis var. chinensis) }\end{array}$ & 0.00 & 6.10 \\
\hline DEM.v1.00043899 & 185.6 & $\begin{array}{l}\text { Similar to MYB113: Transcription factor MYB113 } \\
\text { (Arabidopsis thaliana) }\end{array}$ & 0.00 & 0.00 \\
\hline DEM.v1.00043901 & 185.7 & $\begin{array}{l}\text { Similar to ABC1K1: Protein ACTIVITY of BC1 } \\
\text { complex kinase (Arabidopsis thaliana) }\end{array}$ & 4.33 & 4.23 \\
\hline DEM.v1.00043902 & 185.9 & $\begin{array}{l}\text { Similar to ALS3: Protein ALUMINUM SENSITIVE } 3 \\
\text { (Arabidopsis thaliana) }\end{array}$ & 0.00 & 0.00 \\
\hline DEM.v1.00043903 & 186.0 & $\begin{array}{l}\text { Similar to HD1: Homeobox protein HD1 } \\
\text { (Brassica napus) }\end{array}$ & 0.00 & 0.00 \\
\hline DEM.v1.00043908 & 186.1 & Protein of unknown function & 0.00 & 0.00 \\
\hline DEM.v1.00043909 & 186.1 & Protein of unknown function & 0.00 & 0.00 \\
\hline DEM.v1.00043910 & 186.1 & $\begin{array}{l}\text { Similar to MYB1: Transcription factor MYB1 } \\
\text { (Actinidia chinensis var. chinensis) }\end{array}$ & 0.00 & 0.00 \\
\hline DEM.v1.00043915 & 186.2 & Protein of unknown function & 0.00 & 0.06 \\
\hline DEM.v1.00043916 & 186.2 & $\begin{array}{l}\text { Similar to NAC078: NAC domain-containing protein } 78 \\
\text { (Arabidopsis thaliana) }\end{array}$ & 0.01 & 0.03 \\
\hline DEM.v1.00043918 & 186.4 & $\begin{array}{l}\text { Similar to UGT86A1: UDP-glycosyltransferase } 86 \mathrm{~A} 1 \\
\text { (Arabidopsis thaliana) }\end{array}$ & 9.53 & 10.4 \\
\hline
\end{tabular}


663 Table S1. Primers used in this study.

\begin{tabular}{|c|c|c|}
\hline Purpose & Primer & Sequence (5'-3') \\
\hline \multirow{16}{*}{ CaAN3 mapping } & HRM-10-63_F & CAGGAATTTTTAGATTAGGTTCAGA \\
\hline & HRM-10-63_R & ACCGTCATATTACCTCCCTGAG \\
\hline & SWPm_00416_F & GCAAGTTCTAATGATGGTTGTG \\
\hline & SWPm_00416_R & AGATCCGAAATTTCCACAGTAC \\
\hline & A3-DL-43883_F & GTCAGACACGCCACTAGTTCA \\
\hline & A3-DL-43883_R & CATAATCGGCGATCAACAAC \\
\hline & A3-DL-43895B_F & GCAGACTTCGGTGGTTGAAT \\
\hline & A3-DL-43895B_R & CCAGCATGTTGAGGCATAAT \\
\hline & A3-DL-43895C_F & CCTTCACTGCGTACGGCTAT \\
\hline & A3-DL-43895C_R & GTGCCACTTTCCTTCACCAT \\
\hline & A3-DL-185.7_F & AGGCAATTTTAGGGTCTCTTTTCA \\
\hline & A3-DL-185.7_R & ATTGTTCCCTTGAAACGCAGG \\
\hline & A3-DL-186.4_F & AGTCGATGATTGGAAAATCGGGA \\
\hline & A3-DL-186.4_R & GCCACTGCATCCTCTAATTCGT \\
\hline & A3-DL-187.1_F & TGGTGAAGAAAATGAAATGGAGGTC \\
\hline & A3-DL-187.1_R & TGGACCATTTCACTAAATAACACAA \\
\hline \multirow{20}{*}{ Gene expression analysis } & $P A L \_\mathrm{F}$ & ATTGATTTTTGCAAGAAATCAATTC \\
\hline & $P A L \_\mathrm{R}$ & GCTCCACTTTAGCCCCAC \\
\hline & C4H_F & GATTCCTTCCATTCGGTGTT \\
\hline & C4H_R & СCTTTCTCCGTGGTGTCG \\
\hline & $4 C L \_\mathrm{F}$ & CTGGACCAGTGCTGGCAAT \\
\hline & $4 C L \_\mathrm{R}$ & GGTTACGGGGCAAAGAACAA \\
\hline & CHS_F & GTGGAACCGTTATCCGACTAGCAA \\
\hline & CHS_R & GTATCACTTGGGCCACGGAAAGTA \\
\hline & $F 3 H \_\mathrm{F}$ & ACGCTGATCATCAAGCAGTG \\
\hline & $F 3 H \_\mathrm{R}$ & CTTTTCGGCAACCTCTTCAG \\
\hline & $D F R \_\mathrm{F}$ & AATCGCTCCAGCTGGTCTCATCAT \\
\hline & $D F R \_\mathrm{R}$ & CTAACACAGGGAAGAGGCTGGTTT \\
\hline & $A N S \_F$ & CAAATGCCCACAACCAGAACTAGC \\
\hline & ANS_R & CGCACTTTGCAGTTACCCACTTTC \\
\hline & CaAN2_F & CATAAGCTTCTAGGCAACAGATG \\
\hline & CaAN2_R & TGCACTTGATGAGAAGGTCCG \\
\hline & CaAN3_F & AAGGAAAGGTGCATGGAATG \\
\hline & CaAN3_R & СACCTCTCTTGATATGTGGC \\
\hline & ACTIN_F & AGCAACTGGGACGATATGGAGAAG \\
\hline & $A C T I N \_\mathrm{R}$ & AAGAGACAACACCGCCTGAATAGC \\
\hline \multirow{2}{*}{ VIGS study } & 43895-VIGS_F & CGACGACAAGACCCTCTCGCCTTCTGAGGAAGGTA \\
\hline & 43895-VIGS_R & GAGGAGAAGAGCCCTAAAATTCATCCCAACCACCA \\
\hline \multirow{2}{*}{ Transient overexpression } & 43895-OE_F & CGACGACAAGACCCTATGAATACTCCAATAATCTGTACAACATCG \\
\hline & 43895-OE_R & GAGGAGAAGAGCCCTCTAATTAAGTAGATTCCATATGTCATCCAT \\
\hline
\end{tabular}


666 Table S2. Phenotypes of 24 pepper accessions.

\begin{tabular}{|c|c|c|c|c|c|c|c|c|}
\hline \multirow[b]{2}{*}{ Group } & \multirow{2}{*}{$\begin{array}{c}\text { Code } \\
\text { (Fig. S6) }\end{array}$} & \multirow[b]{2}{*}{ Species } & \multirow[b]{2}{*}{ Accession } & \multicolumn{5}{|c|}{ Phenotype* } \\
\hline & & & & $\begin{array}{c}\text { Immature } \\
\text { fruit }\end{array}$ & $\begin{array}{c}\text { Mature } \\
\text { fruit }\end{array}$ & Flower & Leaf & Stem \\
\hline \multirow{8}{*}{ I } & $\mathrm{a}$ & C. frutescens & IT218962 & $\mathrm{P}$ & $\mathrm{R}$ & $\mathrm{P}$ & $\mathrm{P}$ & G \\
\hline & $\mathrm{b}$ & C. аппиит & KC00134 & $\mathrm{P}$ & $\mathrm{R}$ & $\mathrm{P}$ & $\mathrm{P}$ & G \\
\hline & $\mathrm{c}$ & C. апnиum & AC08-181 & $P$ & $\mathrm{R}$ & $P$ & $\mathrm{P}$ & G \\
\hline & $\mathrm{d}$ & C. аппиит & IT223782 & $\mathrm{P}$ & $\mathrm{R}$ & $\mathrm{P}$ & $\mathrm{G}$ & G \\
\hline & $\mathrm{e}$ & C. аппиит & IT286136 & $\mathrm{P}$ & $\mathrm{R}$ & $\mathrm{P}$ & $\mathrm{G}$ & G \\
\hline & $\mathrm{f}$ & C. аппиит & IT218615 & $\mathrm{P}$ & $\mathrm{R}$ & $\mathrm{P}$ & G & G \\
\hline & $\mathrm{g}$ & C. frutescens & IT301140 & $\mathrm{P}$ & $\mathrm{R}$ & $\mathrm{P}$ & $\mathrm{G}$ & G \\
\hline & $\mathrm{h}$ & C. аппиит & IT158844 & $\mathrm{P}$ & $\mathrm{R}$ & $\mathrm{P}$ & G & G \\
\hline \multirow{4}{*}{ II } & $\mathrm{i}$ & C. аппиит & MAB2 & $\mathrm{P}$ & $\mathrm{R}$ & W & G & G \\
\hline & $j$ & C. аппиит & Mavis & $\mathrm{P}$ & $\mathrm{R}$ & $\mathrm{W}$ & G & G \\
\hline & $\mathrm{k}$ & C. аппиит & Mavras & $\mathrm{P}$ & $\mathrm{R}$ & $\mathrm{W}$ & G & G \\
\hline & 1 & C. аппиит & IT305471 & $\mathrm{P}$ & $\mathrm{R}$ & W & G & G \\
\hline \multirow{4}{*}{ III } & $\mathrm{m}$ & C. апnиит & IT286162 & $\mathrm{P}^{\prime}$ & $\mathrm{R}$ & $\mathrm{W}$ & $\mathrm{G}$ & G \\
\hline & $\mathrm{n}$ & C. chinense & IT158637 & $\mathrm{P}^{\prime}$ & $\mathrm{R}$ & W & G & $\mathrm{P}$ \\
\hline & o & C. chinense & IT229203 & $\mathrm{P}^{\prime}$ & $\mathrm{R}$ & $\mathrm{W}$ & G & G \\
\hline & $\mathrm{p}$ & C. аппиит & AC09-003 & $\mathrm{P}^{\prime}$ & $\mathrm{R}$ & W & $\mathrm{G}$ & G \\
\hline \multirow{8}{*}{ IV } & $\mathrm{q}$ & C. аппиит & KC01237 & G & $\mathrm{R}$ & $\mathrm{W}$ & G & $\mathrm{P}$ \\
\hline & $\mathrm{r}$ & C. апnиum & IT218898 & $\mathrm{G}$ & $\mathrm{R}$ & $\mathrm{W}$ & $\mathrm{G}$ & G \\
\hline & $\mathrm{s}$ & C. аппиит & Chilbok No.2 & G & $\mathrm{R}$ & W & G & G \\
\hline & $\mathrm{t}$ & C. апnиuт & Jeju & $\mathrm{G}$ & $\mathrm{R}$ & $\mathrm{W}$ & $\mathrm{G}$ & G \\
\hline & $\mathrm{u}$ & C. аппиит & IT238052 & G & $\mathrm{R}$ & W & G & G \\
\hline & $\mathrm{v}$ & C. апnиum & Yuwolcho & $\mathrm{G}$ & $\mathrm{R}$ & $\mathrm{W}$ & G & $\mathrm{G}$ \\
\hline & $\mathrm{w}$ & C. аппиит & IT238056 & G & $\mathrm{R}$ & $\mathrm{W}$ & G & G \\
\hline & $\mathrm{x}$ & C. аппиит & MAB1 & G & $\mathrm{R}$ & W & G & G \\
\hline
\end{tabular}


668 Table S3. Primer sequences for the SCAR marker specific for CaAN3.

\begin{tabular}{ll}
\hline Primer & Sequence (5'-3') \\
\hline AN3_IDEL_F & GCGGATCAGATTCATCTTTCATCTAG \\
AN3_INS_R & ATTGAAAACAACATACTTTTCATAAGTATATATTAAATCT \\
AN3_DEL_R & GGTATGGTCGACTGAATATCCTTCA \\
\hline
\end{tabular}

669 


\section{Figure legends}

671

672 Fig. 1. Phenotypes of plant materials and $C a A n 3$ marker analysis. a $C$. annuит lines MAB2 673 and MAB1. MAB2 has purple immature fruits, while MAB1 has green immature fruits. Both 674 lines have green leaves and stems. b Fruit phenotype of $\mathrm{F}_{2}$ plants derived from the hybrid $C$. 675 аппиит Salad Piment Purple. Pigmentation in immature fruits segregates into purple and green 676 immature fruits. $\mathbf{c}$ Genotyping of the mapping population for CaAN2. Plants in the mapping 677 population carry the non-functional $\operatorname{CaAN2}$ allele but still segregate for purple pigmentation. A 678 previously developed SCAR marker set was used for screening CaAN2. Two C. annuит lines 679 were used as controls: 'KC00134' and 'Chilbok No.2' for the CaAN2 functional and non680 functional alleles, respectively

Fig. 2. Genetic mapping of CaAN3 using BSR-seq a Estimation of the candidate interval for 683 CaAN3. A total of 6,672 significant SNPs were identified by calculating $\Delta$ (SNP-index) between 684 the two BSR-seq datasets. The putative genomic region of CaAN3 is indicated in yellow b Finemapping of CaAN3. CaAN3 was mapped to chromosome 10, between 184,603 kb and 186,432 $\mathrm{kb}$. The number of recombinants from $243 \mathrm{~F}_{2}$ individuals is indicated below the black bar. The genotypes of $\mathrm{F}_{2}$ plants homozygous for the green or purple CaAN3 allele or heterozygous are shown as green, purple, and brown bars, respectively. Seven bars at the bottom represent the genotypes of informative individuals with recombination events

691 Fig. 3. Structural variation between the purple and green CaAN3 alleles. a Major sequence 692 variation between the $\mathrm{CaAN3}$ promoter from putative functional and non-functional alleles. 
693 Purple homozygous individuals of Salad Piment Purple $F_{2}$ and MAB2 have identical sequences.

694 Green homozygous individuals of Salad Piment Purple $F_{2}$ and MAB1 have identical sequences.

695 Due to the expression pattern of Dem.v1.00043895, the CaAN3 purple allele is expected to 696 represent a functional allele, while the green $C a A N 3$ allele is non-functional. b Comparison of 697 the predicted protein sequence between two purple alleles and two green alleles

Fig. 4. Silencing the candidate gene (Dem.v1.00043895) via VIGS. a Representative phenotypes of fruits from the wild type (WT), VIGS::GFP, VIGS::PDS, and VIGS::CaAN3 plants. VIGS::GFP and VIGS::PDS plants were used as negative and positive controls, respectively, and only produced purple fruits. VIGS::CaAN3 plants exhibited a partial or complete loss of purple pigment accumulation. Blue arrow indicates bleached leaf, indicating that $P D S$ is properly silenced. Red arrows indicate loss of purple pigmentation in CaAN3silenced fruits. b HPLC analysis of anthocyanidin concentrations in the pericarp. Anthocyanidins were measured by pooling the green (or red) parts of the pericarps sampled from three different fruits. A similar trend was also observed in mature fruits (pool 4). Most of

708 the anthocyanidins measured were delphinidins. c Relative gene expression in the pericarp of 709 fruits silenced for Dem.v1.00043895. Relative expression levels of four early anthocyanin 710 biosynthetic genes ( $C 4 H, 4 C L, C H S, F 3 H)$, three late anthocyanin biosynthetic genes ( $F 3$ '5' $H$, $711 D F R, A N S$ ), and the CaAN3 candidate gene in the pericarps of wild-type, GFP-silenced fruits 712 (negative control), and Dem.v1.00043895-silenced fruits. Asterisks indicate significant 713 difference $(p<0.05)$. 
715 Fig. 5. Expression analysis of CaAN2 (a) and CaAN3 (b) in different pepper accessions. Group 716 I (from IT218962 to IT158844) with both purple fruits and flowers showed relatively high 717 CaAN2 expression but almost no CaAN3 expression. In Group II accessions (from MAB2 to 718 IT305471), CaAN2 was barely expressed while CaAN3 was highly expressed. Group III (from 719 IT286162 to AC09-003) showed low CaAN2 expression and almost no CaAN3 expression. 720 Group IV with no purple pigmentation in either fruits or flowers had the lowest expression 721 levels of $C a A N 2$ and $C a A N 3$.

Fig. 6. Phylogenetic analysis of CaAN2, CaAN3, and tomato R2R3 MYB TFs.

Fig. S1. Transcriptome analysis using fruit-specific DEGs. a GO term enrichment analysis. GO analysis was performed for the three categories biological process, molecular function, and cellular component. b KEGG pathway enrichment analysis, using 2,175 DEGs between green and purple immature fruits. The red box highlights pathways known to be related to anthocyanin 729 biosynthesis.

Fig. S2. Expression of anthocyanin biosynthetic genes in the pericarp of green and purple pools 732 from the $F_{2}$ population derived from the hybrid Salad Piment Purple. a Core anthocyanin 733 biosynthesis pathway in pepper. $P A L$, phenylalanine ammonia lyase; $C 4 H$, cinnamate 4734 hydroxylase; $4 C L$, 4-coumaroyl CoA; $C H S$, chalcone synthase; $C H I$, chalcone isomerase; $F 3 H$, 735 flavonoid 3-hydroxylase; DFR, dihydroflavonol 4-reductase; ANS, anthocyanidin synthase; $3 G T$, flavonoid 3-O-glucosyltransferase. b Expression levels of structural genes in the 
anthocyanin biosynthetic pathway. The numbers indicate gene expression levels as $\log _{2}($ mean

738 FPKM + 1), of each pool.

740 Fig. S3. Physiological changes of MAB2 fruits during development. a Phenotypic changes of 741 fruit pigmentation from 10 to 50 DPA. b Relative Dem.v1.00043895 expression levels as a 742 function of fruit development. $\mathbf{c}$ Changes in concentration of delphinidins in the pericarp. Most 743 of the anthocyanidins measured are delphinidins. d Relative Dem.v1.00043895 expression 744 levels in different tissues. Dem.v1.00043895 showed higher expression levels immature fruit 745 compared to leaves, stems, and flowers at 20 DPA.

747 Fig. S4. Transient overexpression of CaAN3 in N. benthamiana leaves. a Schematic diagram 748 of the CaAN3 effector construct, consisting of the CaAN3 coding sequence placed under the 749 control of the cauliflower mosaic virus $35 \mathrm{~S}$ promoter. b Phenotypic alterations caused by 750 CaAN3 overexpression in N. benthamiana leaves. GFP was overexpressed as a negative control. 751 c Anthocyanin extracts and total anthocyanin contents for each extract measured by 752 spectrophotometry. Each transiently infiltrated leaf sector with 35S:CaAN3 showed some 753 accumulation of anthocyanins over levels detected in $35 S: G F P$ leaves and control non754 infiltrated leaves.

756 Fig. S5. Phenotypes of immature fruits and flowers from 24 pepper accessions. Four phenotypic 757 patterns were observed. $\mathbf{a}-\mathbf{h}$ have both purple fruits and purple pigmented flowers. $\mathbf{i}-\mathbf{l}$ exhibit 758 fruit-specific purple pigmentation. $\mathbf{m}-\mathbf{p}$ display pale purple pigmentation with a yellowish 759 background. q-x have no purple pigmentation in either fruits or flowers. a IT218962 b 
760 KC00134 c AC08-181 d IT223782 e IT286136 f IT218615 g IT301140 h IT158844 i MAB2 j

761 Mavis k Mavras I IT305471 m IT286162 n IT158637 o IT229203 p AC09-003 q KC01237 r

762 IT218898 s Chilbok No.2 t Jeju u IT238052 v Yuwolcho w IT238056 x MAB1.

763

764 Fig. S6. Testing the CaAN3 SCAR marker on 24 pepper accessions. Although there are 765 different expression patterns of CaAN3 among 24 pepper lines, genotypic variation was not 766 correlated. Except for MAB1, most other pepper lines have the identical structure as MAB2 767 with fruit-specific anthocyanin accumulation. IT229203 might harbor another type of promoter 768 structure, since we failed to amplify a PCR product despite several attempts. 


\section{Figures}

\section{Figure 1}

Phenotypes of plant materials and CaAn3 marker analysis. a C. annuum lines MAB2and MAB1. MAB2 has purple immature fruits, while MAB1 has green immature fruits. Bothlines have green leaves and stems. b Fruit phenotype of F2 plants derived from the hybrid C.annuum Salad Piment Purple. Pigmentation in immature fruits segregates into purple and greenimmature fruits. c Genotyping of the mapping population for CaAN2. Plants in the mappingpopulation carry the non-functional CaAN2 allele but still segregate for purple pigmentation. Apreviously developed SCAR marker set was used for screening CaAN2. Two C. annuum lineswere used as controls: 'KC00134' and 'Chilbok No.2' for the CaAN2 functional and non-functional alleles, respectively

\section{Figure 2}

Genetic mapping of CaAN3 using BSR-seq a Estimation of the candidate interval forCaAN3. A total of 6,672 significant SNPs were identified by calculating $\Delta$ (SNP-index) betweenthe two BSR-seq datasets. The putative genomic region of CaAN3 is indicated in yellow $b$ Fine-mapping of CaAN3. CaAN3 was mapped to chromosome 10, between 184,603 kb and 186,432kb. The number of recombinants from 243 F2 individuals is indicated below the black bar. Thegenotypes of F2 plants homozygous for the green or purple CaAN3 allele or heterozygous areshown as green, purple, and brown bars, respectively. Seven bars at the bottom represent thegenotypes of informative individuals with recombination events 


\section{a}

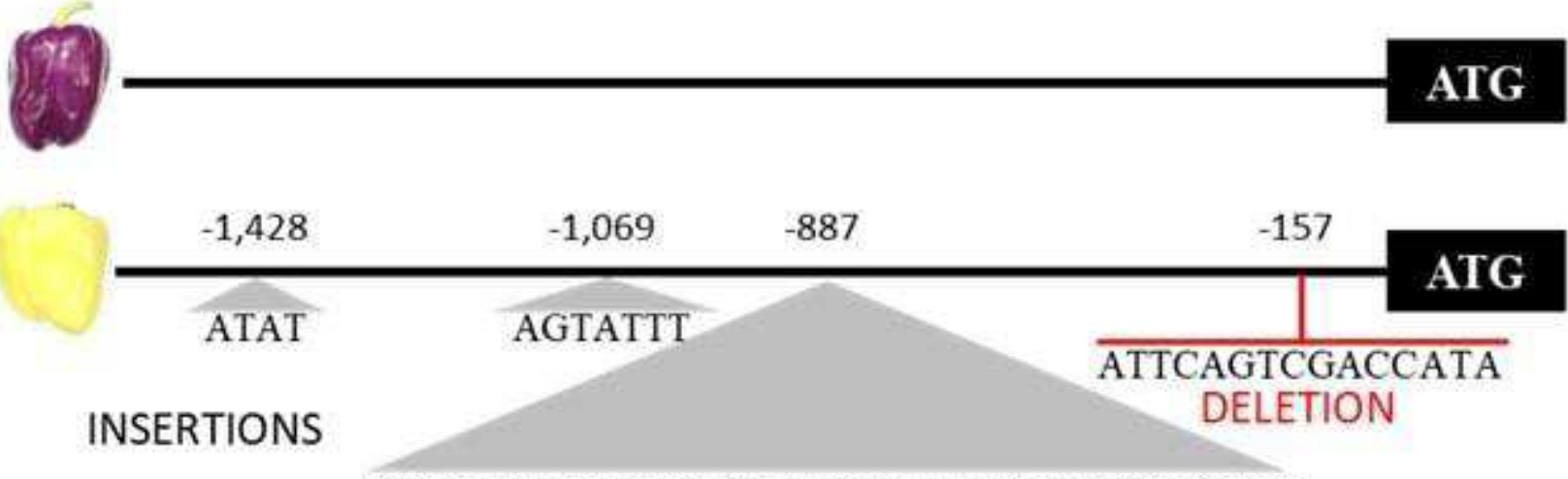

AGATTTAATATATACTTATGAAAACTATGTTGTTT

b MAB1 (Green) S.PF $F_{2}$ (Green) MAB2 (Purple) S.PF $F_{2}$ (Purple)

MAB1 (Green) S.PF $F_{2}$ (Green) MAB2 (Purple) S.PF $F_{2}$ (Purple)

MAB1 (Green) S.PF $F_{2}$ (Green) MAB2 (Purple) S.PF $F_{2}$ (Purple)

MAB1 (Green) S.PF $F_{2}$ (Green) MAB2 (Purple) S.PF $F_{2}$ (Purple)
MNTPI ICTTSLOVRKGAUNEEEDFLLRKCIEKYGEGKWHLUPDRAGLNARCRKSCRLR"WLN 60 MNTPI ICTTSLOVRKGAWNEEEDFLLRKCIEKYGEGKWHLVPDRAGL NRCRKKSCRLRIILN 60

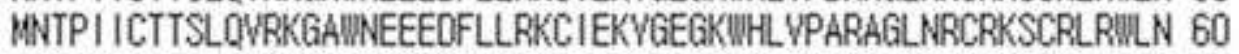
MNTPI ICTTSLQVRKGANINEEEOFLLRKCIEKYGEGKWHLVPARAGLLNRCPKSCRLRWLN 60

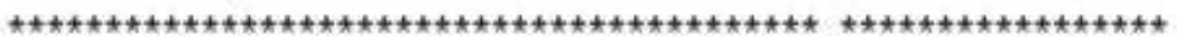

VLRPHIKRGOFDPOEVDLILRLHKLLGNRWILLIAGRLPGRTANOVKNFWNTRLLRKUNIA 120 VLRPHIKRGOFOPOEVOLILRLHKLLGNRWSLIAGGRPGGTANOWNFWNTRLLRKUNIA 120 VLRPHIKRGOFOPOEVOLILRLHKLLGNRWSLIAGRLPGRTANOWNFFWNTRLLRKYNIA 120 VLRPHIKRGOFOPOEYOLILRLHKLLGNRWISLIAGRLPGRTANOWNFWNTRLLRKVNIA 120

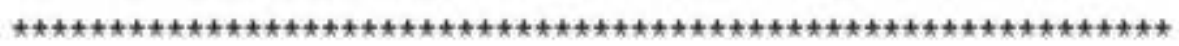

PINNKIGONINTKNEI IRPOPRNFSSTMKNUSWCNNKSI INEANILENCNEIEEÁIATGT 180 PINNK IGDNINTKNEI IRPOPRNFSSTMKNUSWCNNKSI INEANILENCNEIEEAIATGT 180 PINNK IGDNINTKNEI IRPOPRNFSSTMKNYSIICNNKSI INEANILENCNEIEEAIATGT 180 PINNKIGONINTKNEI IRPOPRNFSSTMKNUSUCNNKSI INEANILENCNEIEEAIATGT 180

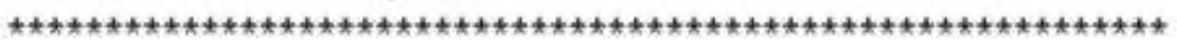

RTPLCKNISSEKNCNEIDKTPCFLNGGGNAMQOGOSOGGMOEFSMOOIWNLLN 233 RTPLCKNISSEKNCNEIDKTPCFLNGGGNAMOQGOSDGGWDEFSMDDI WNLLN 233 RTPLCKNISSEKNCNEIDKTPCFLNGGGNAMOQGOSOGGWDEFSMDOIWNLLN 233 RTPLCKNISSEKNCNEIOKTPCFLNGGGNATOOGOSDGGUIDEFSMDDIWNLLN 233

\section{Figure 3}

Structural variation between the purple and green CaAN3 alleles. a Major sequencevariation between the CaAN3 promoter from putative functional and non-functional alleles. Purple homozygous individuals of Salad Piment Purple F2 and MAB2 have identical sequences.Green homozygous individuals of Salad Piment Purple F2 and MAB1 have identical sequences.Due to the expression pattern of Dem.v1.00043895, the CaAN3 purple allele is expected torepresent a functional allele, while the green CaAN3 allele is non-functional. b Comparison ofthe predicted protein sequence between two purple alleles and two green alleles 
a
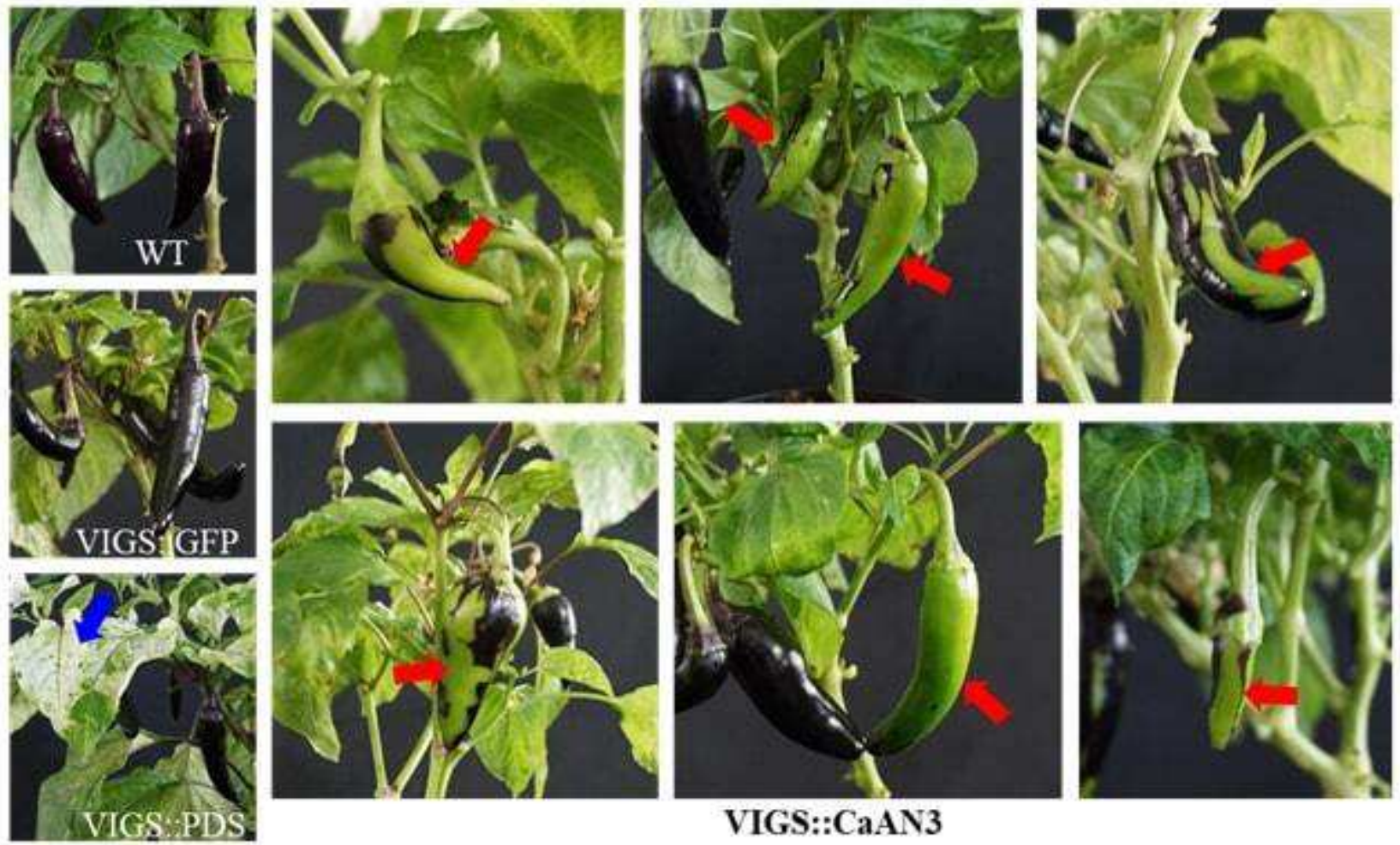

VIGS::CaAN3
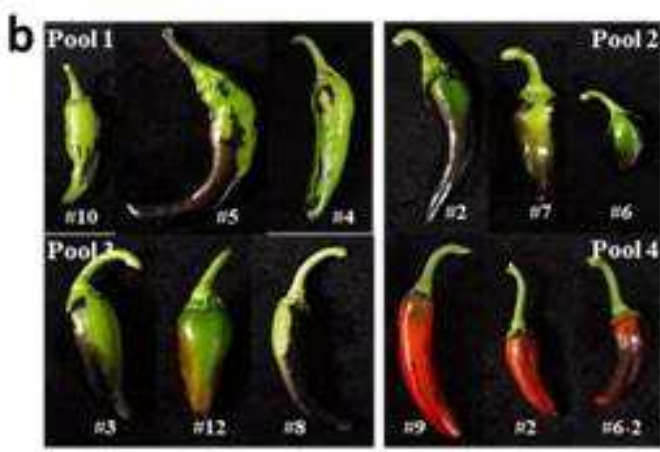

Delphinidin concentration $\left(\mu \mathrm{g} \mathrm{g}^{-1}, \mathrm{DW}\right)$
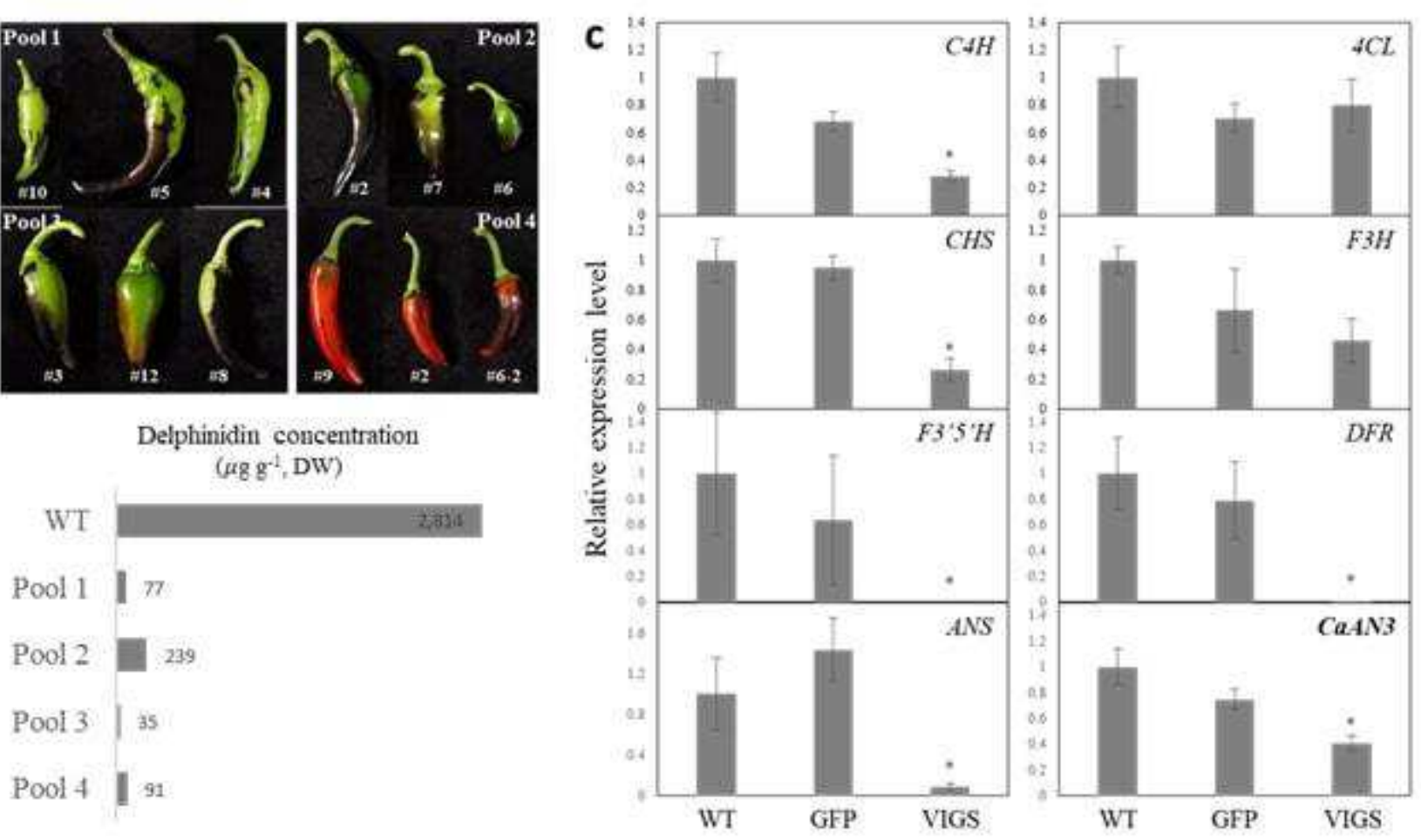

\section{Figure 4}

Silencing the candidate gene (Dem.v1.00043895) via VIGS. a Representativephenotypes of fruits from the wild type (WT), VIGS::GFP, VIGS::PDS, and VIGS::CaAN3plants. VIGS::GFP and VIGS::PDS plants were used as negative and positive controls,respectively, and only produced purple fruits. VIGS::CaAN3 plants exhibited a partial orcomplete loss of purple pigment accumulation. Blue arrow indicates bleached leaf, indicatingthat PDS is properly silenced. Red arrows indicate loss of purple pigmentation in CaAN3- 
silenced fruits. b HPLC analysis of anthocyanidin concentrations in the pericarp. Anthocyanidins were measured by pooling the green (or red) parts of the pericarps sampledfrom three different fruits. A similar trend was also observed in mature fruits (pool 4). Most ofthe anthocyanidins measured were delphinidins. c Relative gene expression in the pericarp offruits silenced for Dem.v1.00043895. Relative expression levels of four early anthocyaninbiosynthetic genes (C4H, 4CL, CHS, F3H), three late anthocyanin biosynthetic genes ( $\left(3^{\prime} 5^{\prime} \mathrm{H}, \mathrm{DFR}, \mathrm{ANS}\right)$, and the CaAN3 candidate gene in the pericarps of wild-type, GFP-silenced fruits(negative control), and Dem.v1.00043895-silenced fruits. Asterisks indicate significantdifference $(p<0.05)$.

\section{Figure 5}

Expression analysis of CaAN2 (a) and CaAN3 (b) in different pepper accessions. Groupl (from IT218962 to IT158844) with both purple fruits and flowers showed relatively highCaAN2 expression but almost no CaAN3 expression. In Group II accessions (from MAB2 tolT305471), CaAN2 was barely expressed while CaAN3 was highly expressed. Group III (fromIT286162 to AC09-003) showed low CaAN2 expression and almost no CaAN3 expression.Group IV with no purple pigmentation in either fruits or flowers had the lowest expressionlevels of CaAN2 and CaAN3.

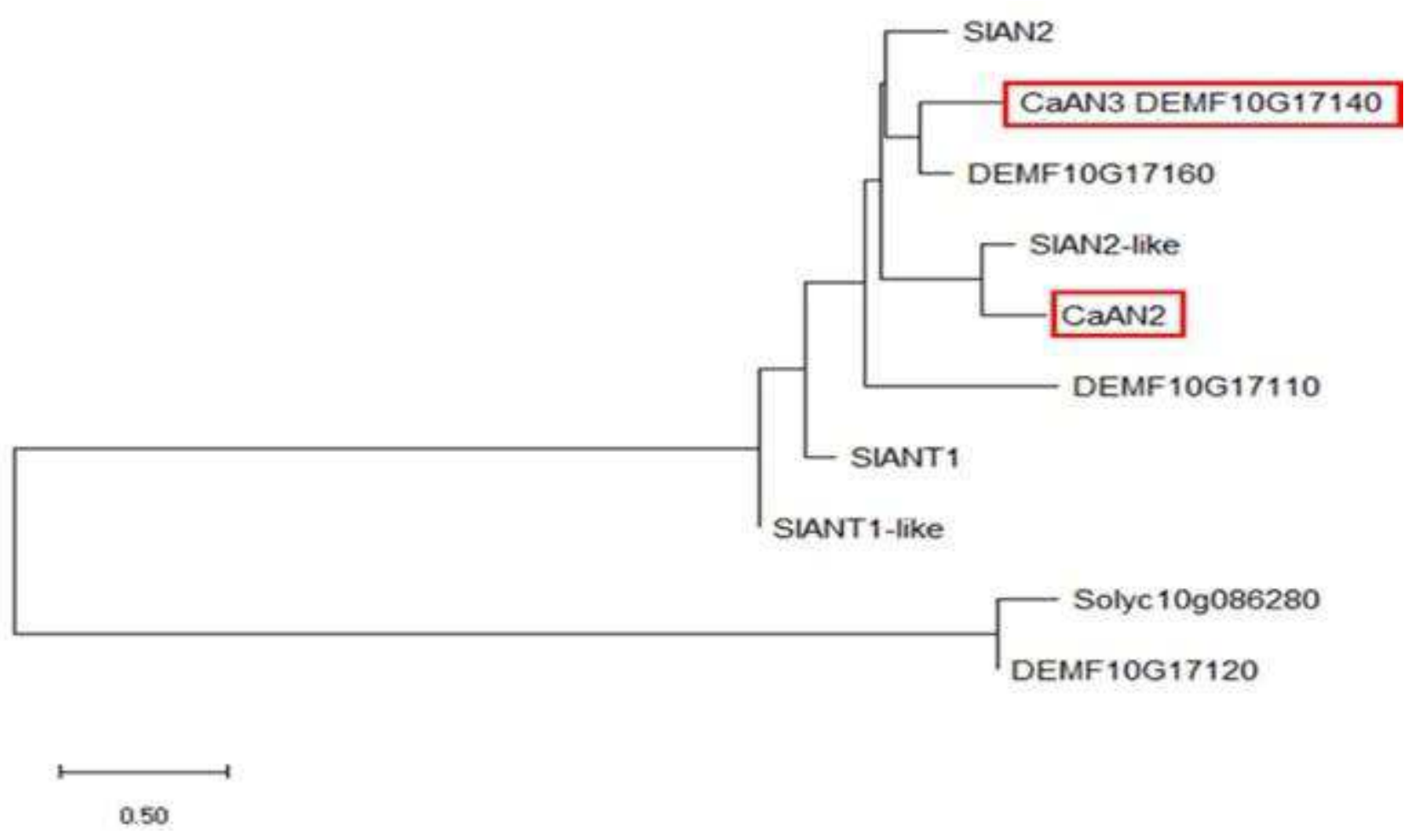

Figure 6

Phylogenetic analysis of CaAN2, CaAN3, and tomato R2R3 MYB TFs.

\section{Supplementary Files}


This is a list of supplementary files associated with this preprint. Click to download.

- Fig.S1.pdf

- Fig.S2.pdf

- Fig.S3.pdf

- Fig.S4.pdf

- Fig.S5.pdf

- Fig.S6.pdf 